\title{
Automation Of An I-V Characterization System
}

\author{
J. R. Noriega* ${ }^{* 1}$, A. Vera-Marquina ${ }^{2}$, C. Acosta Enríquez ${ }^{3}$ \\ ${ }^{1,2,3}$ Departamento de Investigación en Física, \\ Universidad de Sonora \\ Rosales y Blvd. Luis Encinas, \\ Col. Centro, Hermosillo, Sonora, Mexico \\ *bnoriega@cajeme.cifus.uson.mx
}

\begin{abstract}
In this paper, an accurate I-V virtual instrument $(\mathrm{VI})$ that has been developed to characterize electronic devices for research and teaching purposes is demonstrated. The virtual instrument can be used to highlight principles of measurement, instrumentation, fundamental principles of electronics, VI programming, device testing and characterization in wafer or discrete device level. It consists of a Keithley electrometer, model 6514, a programmable power supply BK Precision, model 1770, a Keithley source meter, model 2400-LV, an Agilent digital multimeter, model 34401, a PC computer and LabVIEW software. The instruments are interconnected using an IEEE 488 protocol. The characteristic VI devices graphs are generated from measured data previous computational processing. The instrument is used in basic courses of physical electronics as well as in advance curses of VLSI design and in research work for characterization of semiconductor materials and devices. This paper describes the $\mathrm{VI}$ instrument design, implementation and characterization experiments.
\end{abstract}

Keywords: Electronic equipment, FETs, Transistor, Electronics engineering.

\section{RESUMEN}

En este trabajo se presenta la automatización de un instrumento I-V desarrollado para la caracterización de dispositivos electrónicos en aplicaciones tanto en docencia como en investigación. Este instrumento virtual puede ser usado para ilustrar los principios de la medición, instrumentación, fundamentos de la electrónica, programación, pruebas eléctricas de dispositivos semiconductores y caracterización de dispositivos discretos en substrato. Consiste de un electrómetro Keithley, modelo 6514, una fuente de voltaje programable BK Precision modelo 1770, medidor Keithley modelo 2400-LV, un multímetro digital Agilent modelo 34401 y una computadora PC con software LabVIEW. Los instrumentos son interconectados usando el protocolo IEEE 488. Las curvas características de los dispositivos son graficadas a partir de los datos medidos y previo procesamiento computacional. Este instrumento se usa en cursos de física electrónica y en cursos avanzados de diseño VLSI y en la caracterización de materiales semiconductores y dispositivos. Este artículo describe el diseño del instrumento, implementación y experimentos de caracterización.

\section{Introduction}

Testing and characterization of electronic devices are important part of any design cycle in electronic engineering [1][2][3][4]. As such, testing and characterization require skills and deep understanding of electronic devices operation, operating conditions and handling considerations. The curriculum of the electronic technology program includes courses such as VLSI design, optoelectronic, digital and analog electronics. For these courses, specific lab activities are designed to reinforce learning and skills. Lab activities include on wafer testing, optoelectronic device testing, and general semiconductor devices testing. Most of these experiments require from the student to be able to produce and to analyze current vs. voltage (I-V) characteristics of electronic devices. In order to provide a training experience, as complete as possible, a virtual instrument was developed to provide students and teachers with an accurate testing instrument. This instrument integrates conventional electronic equipment for semiconductor testing, while processing of measured data is carried out by mathematical algorithms implemented on LabVIEW. This virtual instrument provides access to electrical variables like current and voltage of specific testing points around the device under test (DUT). Therefore, students can simulate and 
compare real device performance, retrieve measured variables or parameters and verify theoretical results for device performance. For analog and physical electronics courses such an instrument provides students the means for testing devices characteristics and reinforces semiconductor devices theory. Common experiences include testing diodes and transistors.

For the optoelectronics course, the light-matter interaction in semiconductors is of outmost important theoretical basis [2][5][6]. Students are provided the means to test the optoelectronic devices theory and reinforce basic theoretical knowledge. He-Ne lasers are common light sources available in the lab, normally used for testing optoelectronic devices. He-Ne lasers, polarizers and the I-V virtual instrument are used for training experiments of optoelectronic devices. Microelectronic courses require a more skillful testing experience. The I-V instrument arrangement is being adapted to a probe PSI station. A set of in-wafer devices of known characteristics has been prepared and is ready for advance students in VLSI design courses. In this case, testing needles are adjusted on the wafer surface using a microscope. It is expected that, once finished, this device will allow students to develop skills for testing and understanding of the technological requirements for in-wafer testing such as in industry. By studying the algorithmic block diagram of the instrument, students achieve a deeper understanding of the testing set up and indirectly the operation of electronic devices. On the other hand, data is readily available and can be easily transfer. This helps students during report writing and presentation preparation. In addition, the virtual instrument is presented as a teaching example in electronic instrumentation and measurement courses. The instrument consists of a programmable power supply, an electrometer and a PC computer linked to these instruments via a IEEE 488 device. A block diagram of the instruments hardware is illustrated in Figure 1. The paper is organized in 4 sections. Semiconductor device testing and the measurement process of some electronic devices are illustrated in general in Section 2. Section 3, describes the integration

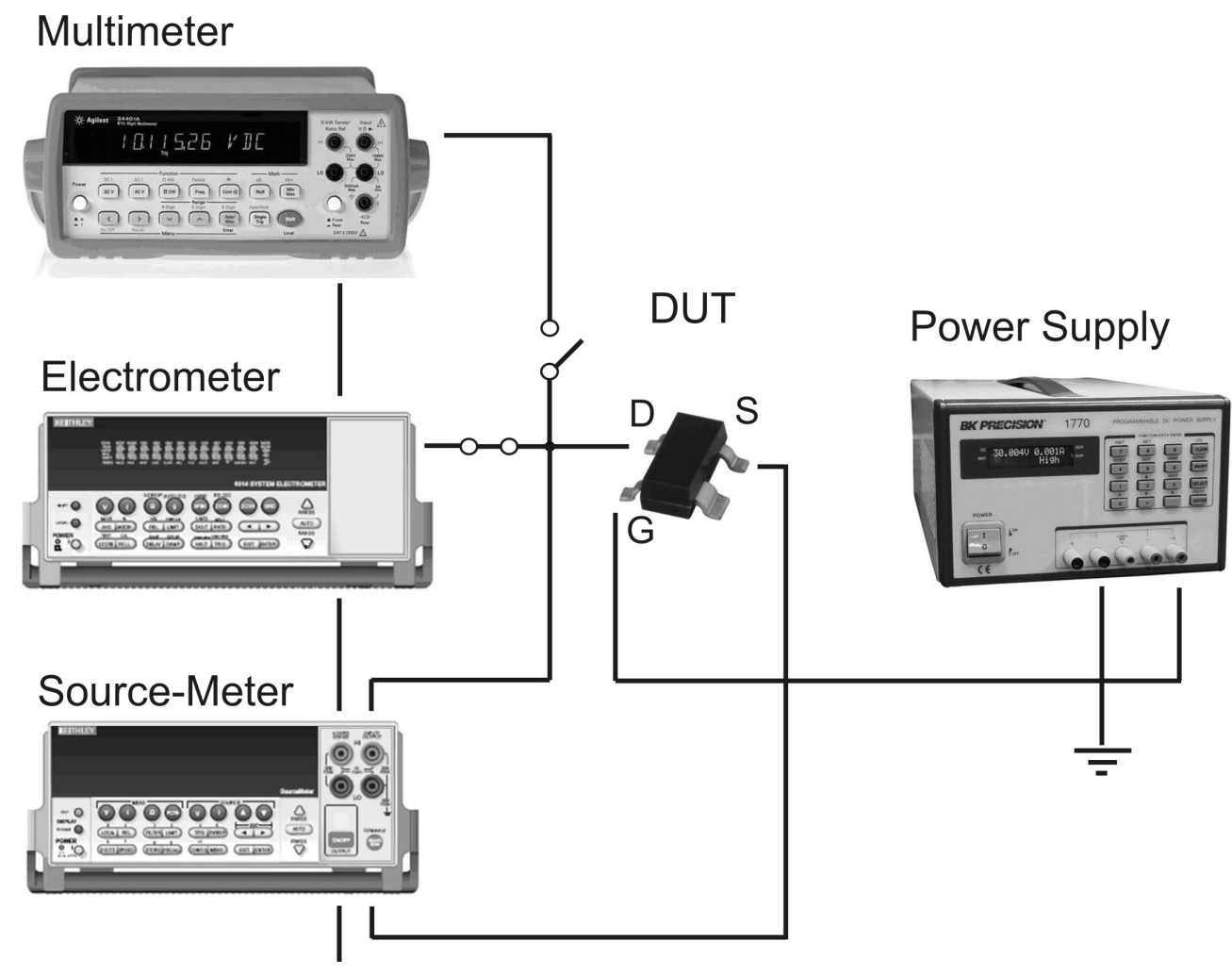

Figure 1. Block diagram of the I-V system. 
and operation of the VI. Hardware is described as well as operational characteristics of the equipment. Block diagrams of the virtual instrument based in LabVIEW language and the virtual instrument display are illustrated in Section 4. Section 5 describes various device models and characteristic curves that can be obtained using the VI. Characterization experiments, setup arrangements and results are discussed also. Conclusions are discussed in detail in Section 6.

\section{Semiconductor device testing}

Semiconductor testing may involve the determination of I-V curves under different schemes. For instance, characteristic I-V curves for a MOS transistor require gate voltage for source-drain current control. In contrast, a BJT transistor requires base current for collector-emitter current control. For FET transistors, the important DC parameters that can be measured using the instrument here described are $g_{m}, r_{d}, \mu, r_{o}$ and $R_{\text {on }}$, [1][2]. All these parameters can be measured by reconfiguring the $\mathrm{VI}$ and the set of instruments in Figure 1 in agreement to the desired parameter.

\subsection{Diode characterization}

For diode testing, the system in Figure 1 only requires a controlled voltage source and ammeter arranged in parallel and series connection, respectively. This allows forward polarization characterization, namely threshold voltage, forward resistance and reverse polarization current testing. The proposed arrangement is illustrated in Figure2.

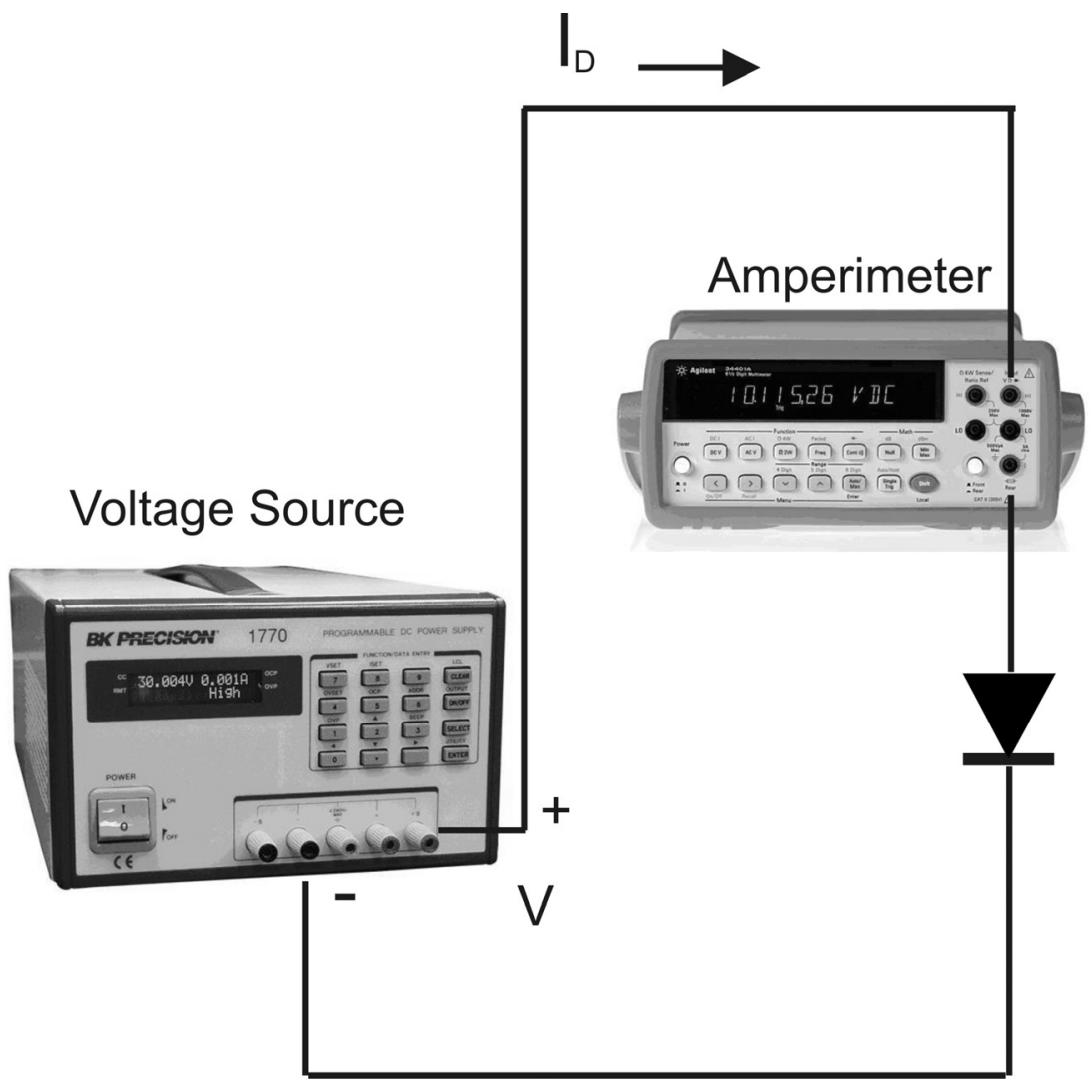

Figure 2. Measurement setup for diode. 
Forward resistance is defined as [2]

$$
R_{f}=\left.\frac{\partial V}{\partial I}\right|_{V>V_{D}}
$$

where $V_{D}$ is the diode on voltage. This equation can be approximated by a difference form, such that measurements of voltage and current can be carried out by pre-programmed finite increments on either voltage or current. Therefore, expression (1) can be rewritten as

$$
R_{f}=\left.\frac{V_{2}-V_{1}}{I_{2}-I_{1}}\right|_{V>V_{D}}
$$

\subsection{Parameters of the fet transistor}

Characterization of a FET transistor is based on the small-signal model illustrated in Figure 3.

Figure 3 shows, in fact, a high-frequency model of a FET transistor including parasitic capacitances. Here, $C_{g s}, C_{g d}$, and $C_{d s}$ are the FET transistor capacitances between gate-source, gate-drain and drain-source, respectively [1][2]. The work described here is only involved with low-frequency or DC testing of semiconductor devices and the parasitics are only included for completeness. Important FET parameters are FET transistor transconductance $g_{m}$, dynamic resistance $r_{d}$, transistor amplification or gain $\mu$ and on resistance $R_{\text {on }}$, [2].

\subsubsection{Transconductance of the fet transistor}

FET transconductance is defined by the gradient of drain-source current to gate-source voltage. This is

$$
g_{m}=\frac{\partial I_{D S}}{\partial V_{G S}}
$$

for measurement purposes the differential operators in equation (3) can be approximated by a difference form. Measurement instruments may then be programmed as to measure the difference of currents and voltages to approximate the FET transconductance $g_{m}$. This expression is

$$
g_{m}=\frac{I_{D S 2}-I_{D S 1}}{V_{G S 2}-V_{G S 1}}
$$

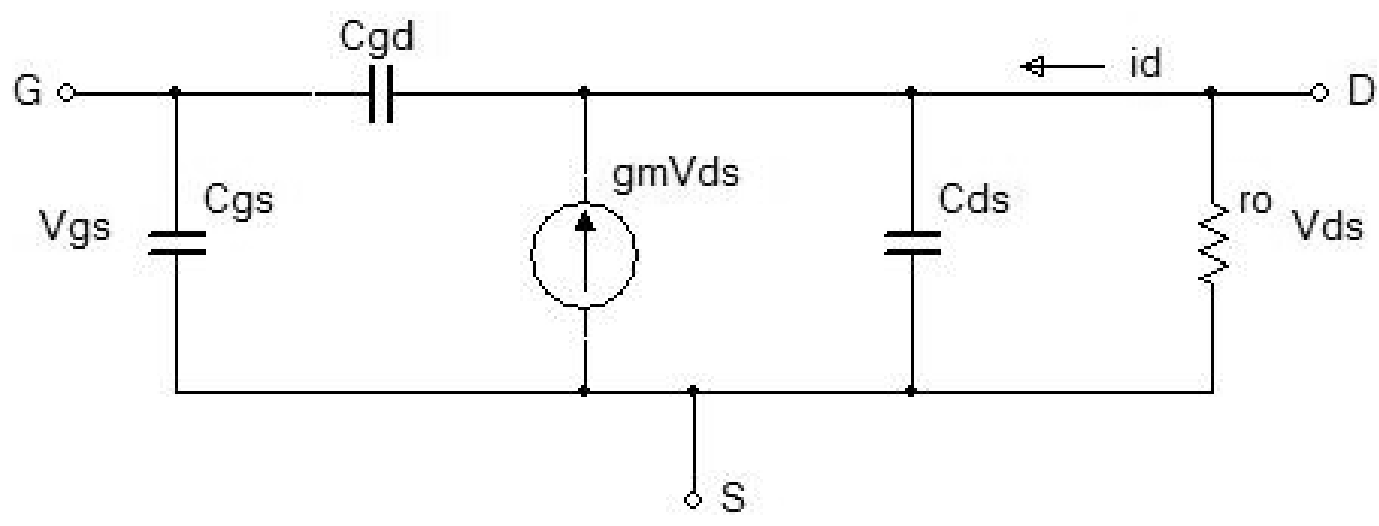

Figure 3. FET transistor model. 
An experimental arrangement for transconductance measurement is illustrated in the block diagram of Figure 4.

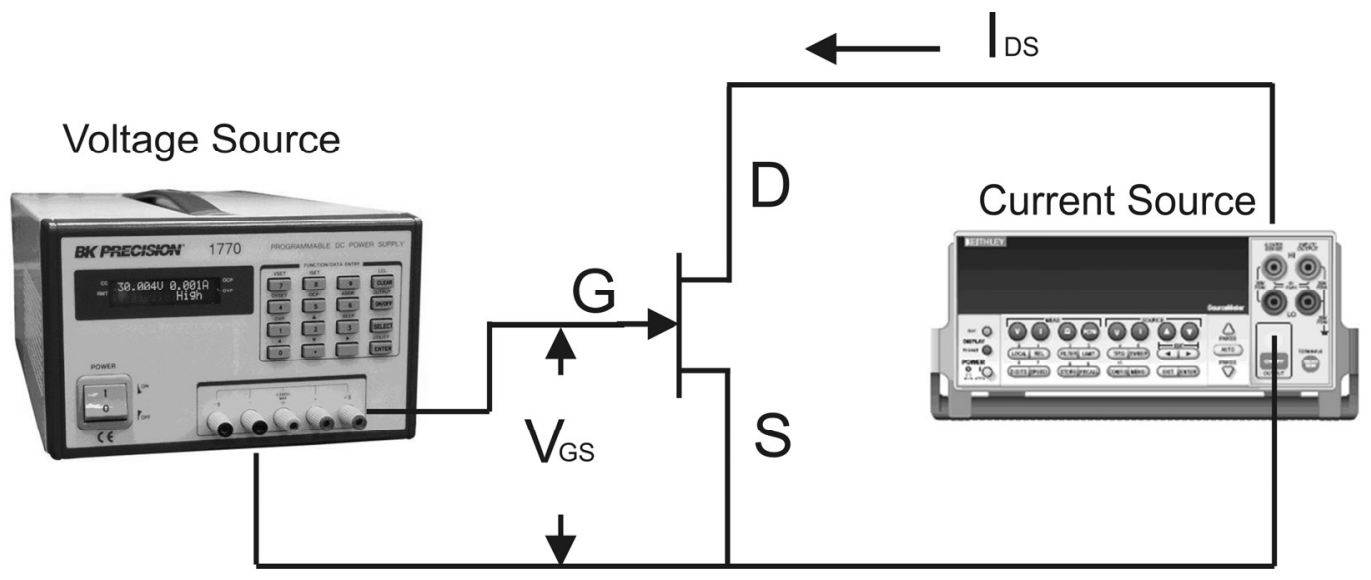

Figure 4. Measurement setup for gm.

Figure 5, is an example that illustrates the measurement of a FET transconductance using the measurement setup shown in Figure 4. Here, measurement of currents $I_{D S 2}$ and $I_{D S 1}$ and voltages $V_{G S 2}$ and $V_{G S 1}$ as required by Equation (4) are highlighted.

\section{VDS[volts]}

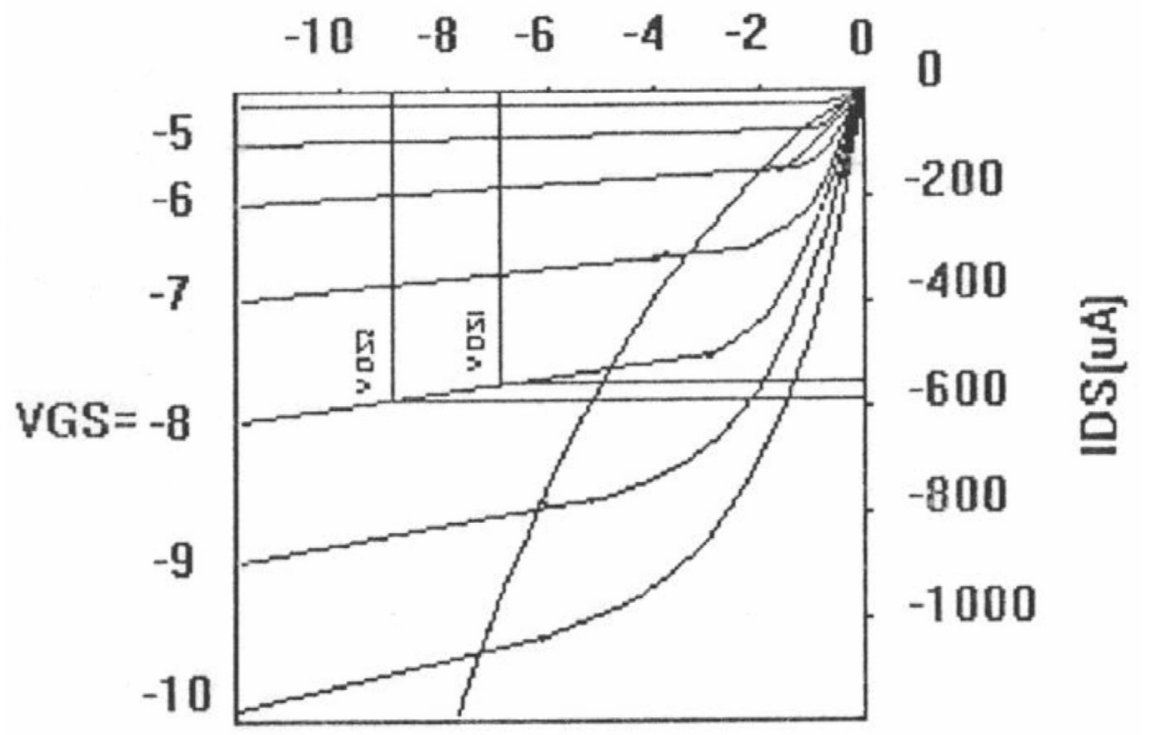

Figure 5. Example PMOS curves showing $I_{D S 2}-I_{D S 1} / V_{G S 2}-V_{G S 1}$ points for $g_{m}$ measurement. 


\subsubsection{Drain resistance}

Drain resistance is defined by the gradient of the drain-source voltage to drain-source current. This is

$$
r_{d}=\left.\frac{\partial V_{D S}}{\partial I_{D S}}\right|_{V_{G S}=\text { const }}
$$

Again, for measurement purposes the differential operators can be approximated by difference operations. Therefore, the FET drain resistance can be measured by programming the system to compute the following expression

$$
r_{d}=\left.\frac{V_{D S 2}-V_{D S 1}}{I_{D S 2}-I_{D S 1}}\right|_{V_{G S}=c o n s t}
$$

Experimental arrangement for the measurement of the $r_{d}$ is illustrated in the block diagram of Figure 4.

\subsubsection{Amplification factor}

The amplification factor for the FET transistor is defined as the gradient of drain-source voltage to gate-source voltage. Therefore

$$
\mu=\left.\frac{\partial V_{D S}}{\partial V_{G S}}\right|_{I_{D S}=\text { const }}
$$

Measurement of $\mu$ can be carried out by to different procedures. As in the measurements described before, a difference form can be used to approximate the partial differential expression of equation (7); therefore, equation (3) takes the form

$$
\mu=\left.\frac{V_{D S 2}-V_{D S 1}}{V_{G S 2}-V_{G S 1}}\right|_{I_{D S}=\text { const }}
$$

On the other hand, measurements of $\mu$ can be computed from previous measurements of $g_{m}$ and $r_{d}$, such that

$$
\mu=g_{m} r_{d}
$$

For this purpose, measurements of $g_{m}$ and $r_{d}$ must have been carried out for the same $I_{D S 2}-I_{D S 1}$ intervals.

\subsubsection{Dynamic resistance}

Dynamic resistance of the FET transistor is defined as

$$
r_{o}=\frac{\partial V_{D S}}{\partial I_{D S}}
$$

Again, writing Equation (10) in the difference form, is therefore approximated as

$$
r_{o}=\frac{V_{D S 2}-V_{D S 1}}{I_{D S 2}-I_{D S 1}}
$$

Experiments are performed for slow-small changes in gate voltage.

\subsubsection{On resistance}

On resistance is important for switching applications. It is defined as

$$
R_{o n}=\frac{1}{\beta\left(V_{G S}-V_{t}\right)}=\frac{1}{g_{m}}
$$

Hence, it is only required to compute the inverse of the measured.

\section{Instrument hardware}

The automated VI hardware consists of an electrometer, a source meter, a precision multimeter and a programmable power supply. These instruments are interconnected using a GPIB interface and LabVIEW software [7][8][9]. The user must identify the testing configuration and procedure for a particular device. The user then proceeds to connect DUT to the instruments according to the testing configuration and selects the testing procedure on the $\mathrm{VI}$ front panel. Electrical connections and instrument 
arrangements are illustrated for a mosfet transistor testing in Figure 4. While the use of commercial individual instruments will add to the cost of the overall system, having NIST-traceable instruments benefits work by providing quality measurements.

\section{Instrument software}

LabVIEW visual-language software has been applied for automation and processing of data of the DUT. In this work, the software used for the VI automation is divided as, instruments control, data processing and display.

\subsection{Instrument control}

All the instruments are connected trough a GPIB bus. A simple piece of LabVIEW software is used to access each instrument either for configuration or data retrieval. Other means of hardware communication can be used for this system; however, since GPIB ports were already incorporated in all of these instruments, GPIB was selected for instruments communication and control. A test is selected on the front panel. These test are predefined in the software, however, the instrument setup must be changed manually in order to retrieve meaningful data. During a test cycle, current and voltage are measured and retrieved trough the GPIB port at predefined increments. The operation parameters are defined at the front panel of the $\mathrm{VI}$ as well as the activation and measurement sequence of each instrument.

\subsection{Data processing}

Computation of the electrical parameters of a DUT requires previous storage of current and voltage measurements. A time for a test cycle is defined, during which, current and voltage are measured at predefined increments. Test cycle time and voltage and current increments are specified by the user. Once these data is stored in memory, they are retrieved and displayed.

\subsection{Instrument display}

The VI display provides the user with fields to input testing parameters and a visual output. The user can select the type of device or test, for instance, the user can select between measuring $R_{f}$ in a diode or to measure $g_{m}$ in a FET transistor. User can also select the measuring cycle parameters such as: initial voltage, final voltage, initial gate voltage, final gate voltage, time and can set a current limit for the DUT. The user gets a light to indicate end-of-testing cycle, current limit reached, and graphical display of the DUT curves. In addition a matrix of I-V measurements is displayed on demand or stored in a file. The VI instrument front panel is shown in Figure 6.

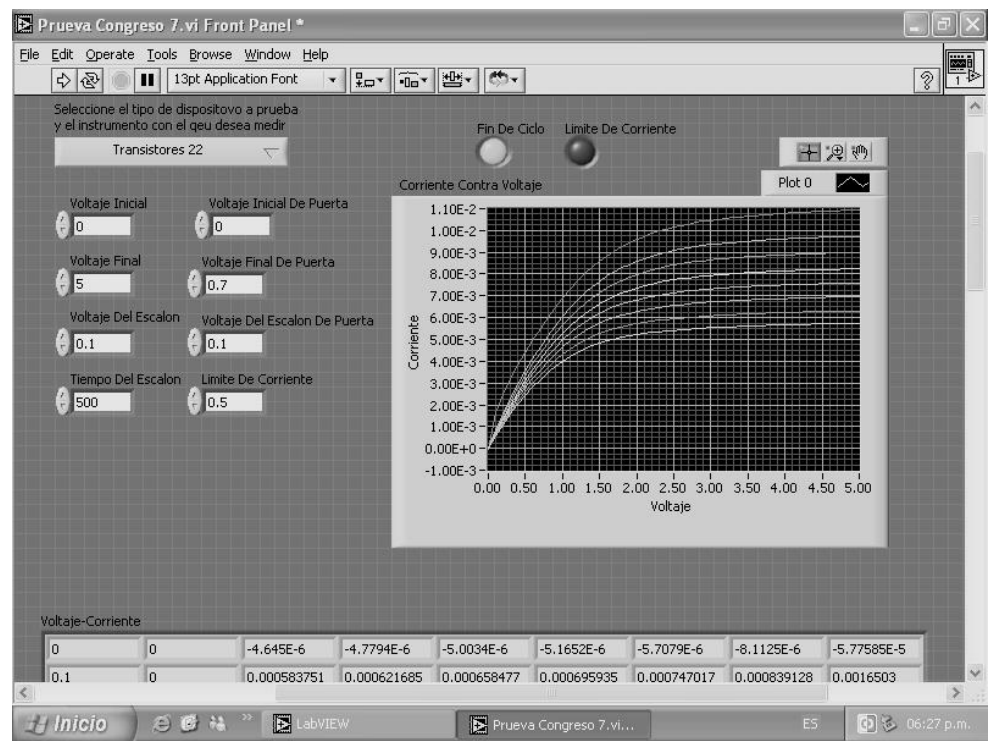

Figure 6. Screen shot of the front panel of the VI. 


\section{Experiments}

Three experiments were carried out to demonstrate the system performance. A custom made four quadrant sensor was characterized producing forward and reverse polarization curves. I-V curves for a 2N4416 FET and a NTE222 MOSFET transistor were produced and compared with data from the manufacturer.

\subsection{Diode i-v characteristics}

Characterization of a four-quadrant photodiode detector was carried out. Reverse polarization response is illustrated in Figure 7.

Here, forward response characteristics of all four photodiodes are registered. For this purpose an experimental setup similar to Figure 2 was implemented. For the inverse polarization response, the measurement setup was the same, but the polarization voltage was reversed. In this case the ammeter was replaced by the electrometer, since photodiode currents are very small. The photodiodes were exposed to laser light from a HeN laser having a nominal output power of $2 \mathrm{~mW}$. For measurement purpose, the laser light was attenuated using a beam polarizer and a power meter for calibration. Hence, laser light coming out of the polarizer could be attenuated by a pre-defined intensity step. For the experiments, the intensity of the laser was adjusted in $0.2 \mathrm{~mW}$ increments. The resulting photodiode currents recorded are illustrated in Figure 8.

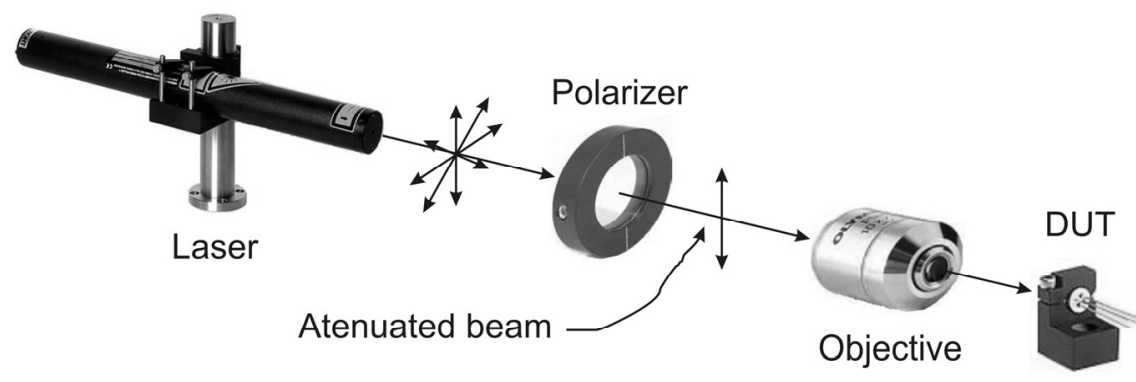

Figure 7. Photodiode experimental arrangement.

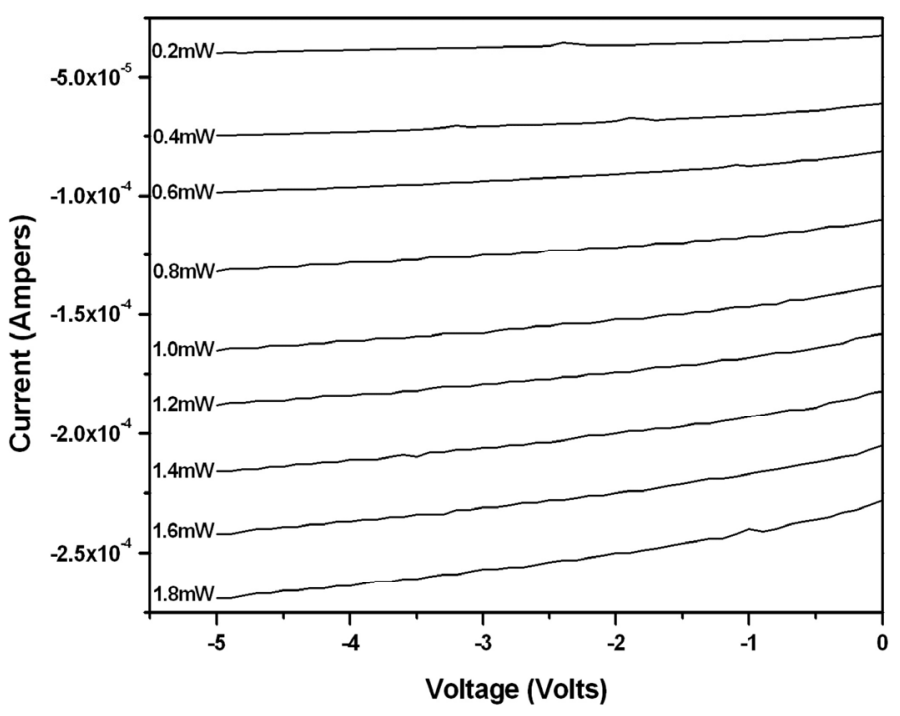

Figure 8. Inverse photodiode current characterization. 


\subsection{Jfet transistor $i-v$ characteristics}

A JFET transistor 2N4416 was characterized. For this purpose a voltage applied to the drain source pins, sweeping from 0 to 5 volt was supplied and programmed to change on 0.1 volts increments. At the same time, voltage applied to gate-source terminals was changed from -0.3 to -1.8 volts in pre-programmed increments of -0.3 volts. This corresponds to setup in Figure 4. The characteristic response curves of the 2N4416 obtained with this instrument are illustrated in Figure 9.

\subsection{Mosfet transistor i-v characteristics}

Characteristic curves of a MOSFET transistor, NTE222 were measured. The characteristic curves for this device where produced by applying a sweep voltage to the drain-source terminals of the device, changing from 0 to 5 volts in preprogrammed increments of 0.1 volts. Simultaneously, a sweep voltage applied to the gate-source terminals changed from 0 to 3.2 volts in pre-programmed increments of 0.4 volts. The corresponding characteristic curves of the NTE222 are illustrated in Figure 10.

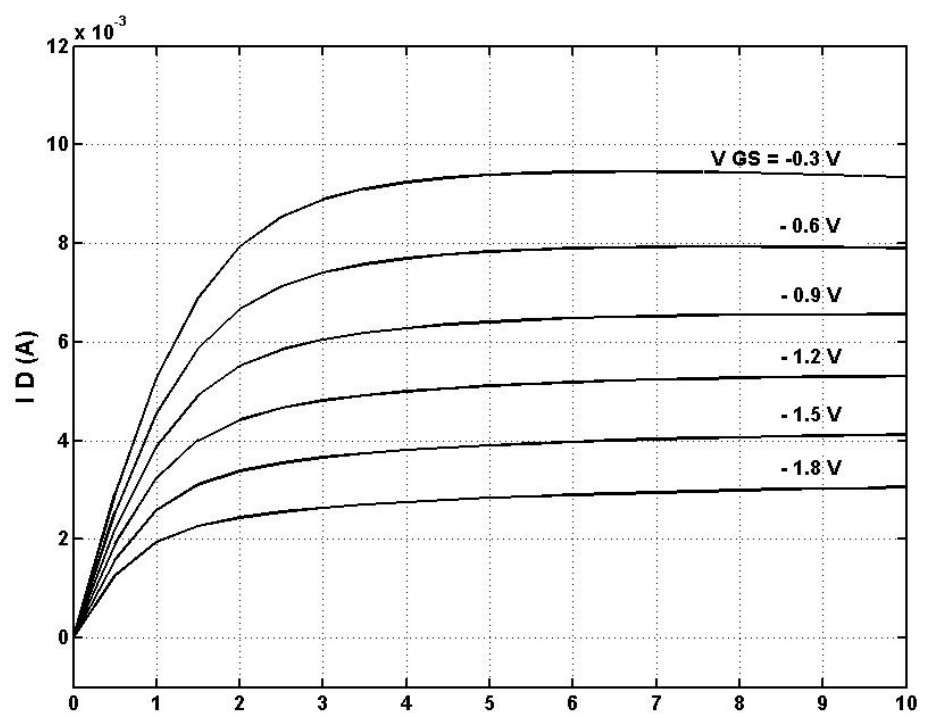

Figure 9. Characteristic curves of the 2N4416.

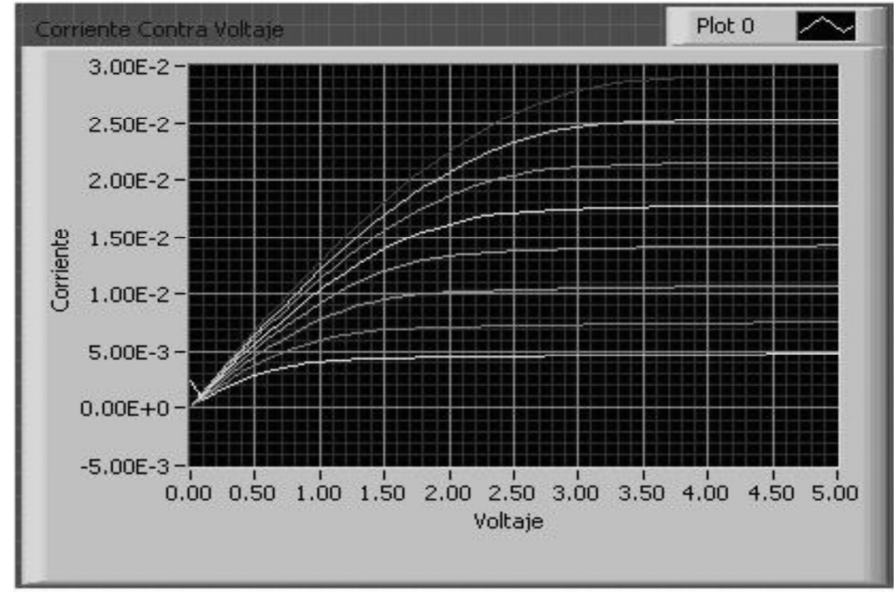

Figure 10. Characteristic curves of the NTE222. 
From this data the parameters of the NTE222 resulted as $g_{m}=9.1 \mathrm{mmho}, \quad r_{d}=1.6 \mathrm{k}, r_{o}=$ 103.7, $R_{\text {on }}=108.8$ and $\mu=15.2$.

\section{Conclusion}

An automatic system for the characterization of semiconductor devices is demonstrated. The system is used as a complement tool for training in different subjects of electronics engineering and research. In this regard, the I-V instrument has been used for demonstration purposes of basic theory of electronic devices in analog electronics courses using bulk diodes and transistors and in advance digital CMOS courses using 10 micrometer technology silicon wafer devices. Students have participated in research work and graduated using this instrument for the characterization of a four quadrant detector and for the characterization of solar cells. This instrument is currently being applied for research work in the characterization of thin film transistors. The tool is flexible since it can be programmed to perform different testing experiments and it can be reconfigured by selecting or including different measurement instruments. Devices that can be characterized with this instrument are diodes, FET and MOSFET transistors, BJT transistors, photodiodes, and phototransistors, amongst other devices. Further work is related to software changes to adapt the instrument for operating point characterization and CMOS inverter transfer function characterization. Overall, the system described in this work is less expensive than commercial instruments with similar functionality.

\section{References}

[1] Microelectronics Series, MOS Integrated Circuits Theory, Fabrication, Design and Systems Applications of MOS LSI, the Engineering Staff of American Microsystems Inc.
[2] J. Millman and C. C. Halkias, Integrated Electronics: Analog and Digital Circuits and Systems, 1st Edition, Tokyo, JAPAN: McGRAWHILL KOGAKUSHA, Electrical and Electronic Engineering Series, 1972.

[3] F.S. Sellschopp and Marco A. Arjona, An Automated System for Frequency Response Analysis with Application to an Undergraduate Laboratory of Electrical Machines, IEEE Transactions on Education, Vol. 47, No. 1, February 2004.

[4] A. Bruce Buckman, VI-Based Introductory Electrical Engineering Laboratory Course, The International Journal of Engineering Education, Vol. 16, No. 3, 2000.

[5] Masahiro Toyoda, Kenichi Araki and Yoshiaki Suzuki, Measurement of the Characteristics of a Quadrant Avalanche Photodiode and Its Application to a Laser Tracking System, Optical Engineering Vol. 41, No. 1, January 2002.

[6] Xunjun Qi and Bin Lin, Design, Realization and Characterization of a Position Sensitive Detector for Fast Optical Measurement, Optical Engineering, Vol. 45, No. 1, January 2006.

[7] J. Travis and J. Kring, LabVIEW for Everyone:graphical programming made easy and fun, 3rd ed. Indiana, USA: Prentice-Hall, 2007.

[8] J. W. Johnson and R. Jennings, LabVIEW Graphical Programming, 4th ed. New York, USA: McGraw-Hill, 2006.

[9] L.F. Noriega, A. Vera and M. Acosta, Automatización de un Sistema de Caracterización de Dispositivos Electrónicos, Congreso de Instrumentación SOMI XXII. Monterrey, Nuevo León, México: SOMI, 2007.

\section{Acknowledgments}

Authors are most thankful to SEP (Mexico's National Council for Education) for partial support of this work trough project PIFI 2007. Technical help from Fernando Noriega and Isidro Granillo is also appreciated. 


\section{Authors' Biographies}

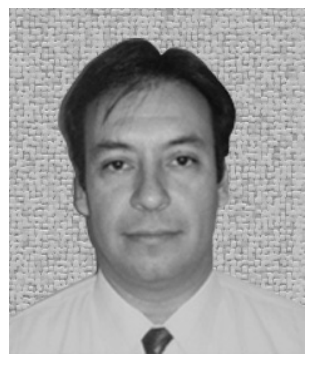

\section{José Rafael NORIEGA}

José Rafael Noriega received the BSc degree from Instituto Tecnológico de Hermosillo (ITH), Mexico, in 1989 and the PhD degree from the University of Manchester (the Institute of Science and Technology), UK, in 1997. From 2000 to 2007, he was head of the Electronic Engineering Technology Program at Universidad de Sonora in Hermosillo, Mexico. He has been a lecturer in the Bachelor of Science Degree Program in Electronic Engineering Technology for the past seven years and is one of the founder professors of this program. His main teaching subjects are digital control and instrumentation. His main interests are the application of artificial neural networks in control systems and fault diagnosis and the design and development of electronic instrumentation. He is currently visitor researcher at University of Texas in Dallas.

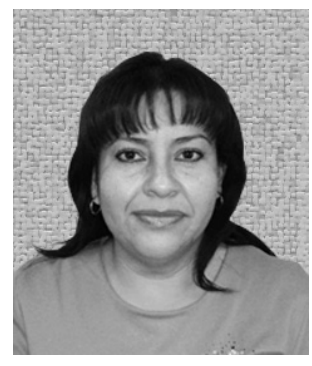

\section{Alicia VERA-MARQUINA}

Dr. Vera-Marquina received her BS degree in electronics from the Benemérita Universidad Autónoma de Puebla, Mexico, in 1994, and her MS degree from the Instituto Nacional de Astrofísica, Óptica y Electrónica (INAOE), Puebla, Mexico, in 1997. She received a PhD in sciences from INAOE in 2001. She worked on the Large Millimeter Telescope (GTM) Project at INAOE from 2000 to 2002. Currently, she is a researcher at the Universidad de Sonora. Her research fields are in digital optical processing, silicon-based optoelectronics, and CMOS design.

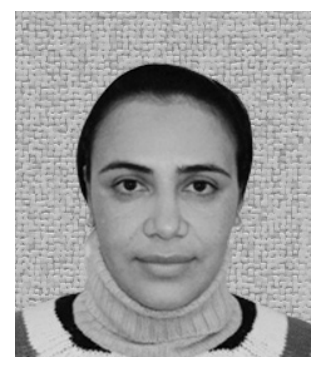

\section{Milka del Carmen ACOSTA-ENRÍQUEZ}

Dr. Acosta-Enríquez was born in Sonora, Mexico. She received the B.S. degree in electronic engineering in 1999 from the Instituto Tecnológico de Sonora, and the M.S. and Ph.D. degrees in electronic and telecommunications from the Centro de Investigación Científica y de Educación Superior de Ensenada, Baja California, Mexico, in 2000 and 2006, respectively. In 2006 she joined the Physics Research Department of the Universidad de Sonora and is now a researcher. She is currently involved in research on optical communications devices and materials. 